[Agr. Biol. Chem., Vol. 29, No. 5, p. 395 402, 1965]

\title{
Studies on Metabolism of Pyrrolidone Carboxylic Acid in Bacteria
}

\author{
Part I. Accumulation of L-Glutamic Acid by Bacteria in the \\ Presence of Pyrrolidone Carboxylic Acid
}

\author{
By Yoshio KawaI*, Yasuo Kawai and Teijiro Uemura \\ Laboratory of Microbiology, Faculty of Agriculture, Tohoku University *Sanko Co., Ltd. \\ Received September 30, 1964
}

\begin{abstract}
The present investigation is concerned with L-glutamic acid production in the presence of pyrrolidone carboxylic acid and glucose in Bacillus megaterium st. 6126. This strain does not grow on DL-pyrrolidone carboxylic acid (DL-PCA) ${ }^{11}$ as the sole source of carbon and nitrogen. The optimal concentration of yeast extract required for the maximal production of L-glutamic acid was $0.005 \%$ under the conditions used. As the yeast extract concentration was increased, growth increased proportionally; but the L-glutamic acid production did not exceed the control's to which glucose and ammonium chloride had been added. L-Glutamic acid produced by both growing cultures and resting cells was derived from glucose and ammonium salt of DL-PCA. Isotope experiments suggested that the L-glutamic acid produced was partially derived from ammonium salt of DL-PCA in the growing culture which had been supplemented with D-glucose-U-14C or DL-PCA-1-14C and that ammonium salt of DL-PCA was consumed as the source of nitrogen and carbon for Lglutamic acid.
\end{abstract}

\section{INTRODUCTION}

Only a little is known about bacterial action on pyrrolidone carboxylic acid (PCA). Y. Maruyama and $\mathrm{M}$. Nomura ${ }^{21}$ have determined that L-PCA is well metabolized by some strains of Pseudomonas to succinic acid through a possible mediation of pyroglutaramic acid. Because of the resemblance of PCA's structure to that of L-glutamic acid's, it may be conceivable that PCA has some effect on the amino acid metabolism, especially on the formation of L-glutamic acid in bacterial cells which can assimilate PCA as the nitrogen or carbon source. On this assumption, the metabolic activity of bacteria on PCA was studied. Several strains of bacteria including Bacillus megaterium, Pseudomonas sp. and Azotobacter sp.

1) Y. Kawai, J. Chem. Soc. Japan, 80, 647 (1959); 80, 1317 (1959); 81, 934 (1960).

2) Y. Maruyama and M. Nomura, J. Biochem. (Japan), 43, 327 (1956). were obtained as good metabolizer of PCA in the presence of glucose. Of these strains, B. megaterium st. 6126 was selected for more extensive studies because of its formation of high amounts of L-glutamic acid from glucose and ammonium chloride and to test the effect of PCA on this formation of L-glutamic acid. The present report deals with some of the results obtained.

\section{MATERIALS AND METHODS}

\section{Microorganisms}

Eighteen bacterial strains were tested for screening. They were isolated in this laboratory and recognized as producers of considerable amounts of certain amino acids if grown on appropriate media. Of these strains, B. megaterium st. 6126 was selected as a good metabolizer of DL-PCA in the presence of glucose, producing L-glutamic acid. This strain, however, cannot grow in PCA medium if glucose is absent, and thus cannot utilize PCA as the sole source of 
carbon and nitrogen.

\section{Media}

(1) Media for screening were as follows: (a) $0.5 \%$ DL-PCA, $\quad 0.15 \% \quad \mathrm{~K}_{2} \mathrm{HPO}_{4}, \quad 0.05 \% \quad \mathrm{MgSO}_{4} \cdot 7 \mathrm{H}_{2} \mathrm{O}$, $0.001 \% \mathrm{FeSO}_{4} \cdot 7 \mathrm{H}_{2} \mathrm{O}, \quad 0.001 \% \mathrm{MnSO}_{4} \cdot n \mathrm{H}_{2} \mathrm{O}, \quad 0.05 \%$ yeast extract, (b) $3 \%$ glucose and $1 \%$ DL-ammonium pyrrolidone carboxylic acid in place of $0.5 \%$ DL-PCA in medium.

(2) Seed culture medium for $B$. megaterium st. o.126: $3 \%$ glucose, $0.15 \% \quad \mathrm{KH}_{2} \mathrm{PO}_{4}, 0.05 \% \quad \mathrm{MgSO}_{4}$. $7 \mathrm{H}_{2} \mathrm{O}, 0.5 \%$ yeast extract, $1 \%$ casamino acids ( $\mathrm{pH} 7.0$, adjusted with $\mathrm{NaOH}$ ).

(3) Culture medium containing PCA for $B$. megaterium st. 6126 : $3 \%$ glucose, $1 \% \mathrm{NH}_{4} \mathrm{Cl}$ or $1 \%$ DL-ammonium pyrrolidone carboxylic acid, $0.15 \%$ $\mathrm{KH}_{2} \mathrm{PO}_{4}, \quad 0.15 \% \quad \mathrm{~K}_{2} \mathrm{HPO}_{4}, \quad 0.05 \% \quad \mathrm{MgSO}_{4} \cdot 7 \mathrm{H}_{2} \mathrm{O}$, $0.001 \% \mathrm{FeSO}_{4} \cdot 7 \mathrm{H}_{2} \mathrm{O}, 0.001 \% \quad \mathrm{MnSO}_{4} \cdot n \mathrm{H}_{2} \mathrm{O}, 0.001 \sim$ $0.5 \%$ yeast extract.

(4) Medium for resting cell experiments: $0.2 \mathrm{M}$ glucose, $0.1 \mathrm{M}$ DL-ammonium pyrrolidone carboxylic acid, M/15 phosphate buffer. All media were adjusted to $\mathrm{pH} 7.0$ with $\mathrm{NaOH}$.

\section{Culture Methods}

(1) Screening test: Three $\mathrm{ml}$ of screening medium was introduced into sterile test tubes, inoculated with a loopful of cells of each test strain and incubated with shaking at $30^{\circ} \mathrm{C}$ for $72 \sim 96$ hrs.

(2) Seed culture: Three $\mathrm{ml}$ of seed culture medium was distributed into sterile test tubes, inoculated with a loopful of cells of $B$. megaterium st. 6126 and incubated with shaking at $30^{\circ} \mathrm{C}$ for $24 \mathrm{hrs}$.

(3) Growing culture experiments: Cells were harvested from the seed culture, washed twice with sterile water, and resuspended in same to prepare an inoculant. Fifty $\mathrm{ml}$ of culture medium was introduced into $500 \mathrm{ml}$ flasks, inoculated with two $\mathrm{ml}$ of the above washed cell suspension and incubated with shaking at $30^{\circ} \mathrm{C}$ for a requisite period.

(4) Resting cell experiments. Cells grown in culture medium were harvested by centrifugation, washed twice with sterile water, and resuspended in three $\mathrm{ml}$ of the incubation medium. Three $\mathrm{ml}$ of reaction mixture was aerobically incubated in a Monod-type tube at $30^{\circ} \mathrm{C}$ for a requisite period.

Estimation of Growth: Bacterial growth was estimated by measuring the optical density at $660 \mathrm{~m} \mu$.

Assay of L-Glutamic Acid and DL-PCA: L-Glutamic acid was usually measured by the pulp disc method ${ }^{3}$ )

3) H. Kojima and N. Matsuya. J. Agr. Chem. Soc, Japan, 32, 100 (1958). using Leuconostoc mesenteroides, or manometrically with L-glutamate decarboxylase of $E$. coli. DL-PCA was measured as glutamic acid by paper chromatógraphic method of Giri4) after hydrolysis at $100^{\circ} \mathrm{C}$ for 1 hour with $4 \mathrm{~N} \mathrm{HCl}$.

Estimation of Glucose: Glucose remaining in the medium was estimatëd by Somogyi's method.5)

D-Glucose-U-14C: D-gluc 3 se-U-14 C of Daiichi Chemicals Co. was used.

DL-PCA-1-14C: DL-PCA-1-14C was synthesized from DL-glutamic acid-1-14 $\mathrm{C}$ of Daiichi Chemicals Co.

\section{RESULT AND DISCUSSION}

\section{Effect of Yeast Extract Concentration on L. Glutamic Acid Production}

Bacillus megaterium st. 6126, which was previously recognized in our laboratory as a strain capable of accumulating L-glutamic acid in glucose-ammonium chloride medium, was selected as a good metabolizer of PCA in the presence of glucose. Some of the results obtained by screening the bacterial strains which metabolized PCA well are indicated in Table $I$, which, in addition to these, includes some of the bacterial strains which could utilize PCA as the sole source of nitrogen and carbon, as previously reported by Maruyama and

TABLE I. SCREENING OF L-GLUTAMIC ACID-Producing Bacteria

Culture time 96 hours

\begin{tabular}{|c|c|c|c|c|}
\hline Strains & $\begin{array}{l}\text { glucose } \\
\mathrm{A}\left(\mathrm{NH}_{4}\right)\end{array}$ & $\begin{array}{l}+ \text { DL- } \\
\text { Medium }\end{array}$ & glucos & $\begin{array}{l}+\underset{\mathrm{NH}}{\mathrm{N}} \mathrm{C} \mathrm{C} \\
\text { dium }\end{array}$ \\
\hline & $\begin{array}{l}\text { growth } \\
-\log T)\end{array}$ & $\begin{array}{c}\text { L-GA } \\
(\mathrm{mg} / \mathrm{ml})(\end{array}$ & $\begin{array}{l}\text { growtl } \\
(-\log 7\end{array}$ & $\begin{array}{r}\text { L-GA } \\
\mid \mathrm{mg} / \mathrm{ml}\end{array}$ \\
\hline B. megaterium 6123 & 1.9 & 0.46 & 3.4 & 2.55 \\
\hline B. megaterium 6124 & 1.14 & 4.5 & 1.04 & 0.98 \\
\hline B. megaterium 6125 & 1.76 & 7.9 & 1.17 & 3.4 \\
\hline B. megaterium 6126 & 1.86 & 10.0 & 0.86 & 3.6 \\
\hline \multirow{2}{*}{\multicolumn{2}{|c|}{ Strains }} & \multicolumn{3}{|c|}{$\begin{array}{l}\text { Culture time } 96 \text { hours } \\
\text { DL-PCA Medium }\end{array}$} \\
\hline & & $\left(\begin{array}{l}\text { growth } \\
(-\log T)\end{array}\right.$ & \multicolumn{2}{|c|}{$\underset{(\mathrm{mg} / \mathrm{ml})}{\mathrm{L}-\mathrm{GA}}$} \\
\hline \multicolumn{2}{|l|}{ Azotobacter A 0112} & 1.58 & \multicolumn{2}{|c|}{0.25} \\
\hline \multicolumn{2}{|l|}{ B. megaterium 6045} & 0.76 & \multicolumn{2}{|c|}{0.60} \\
\hline \multicolumn{2}{|l|}{ B. megaterium 6127} & 0.72 & \multicolumn{2}{|c|}{0.70} \\
\hline \multicolumn{2}{|c|}{ B. megaterium $G-17-4$} & 0.88 & \multicolumn{2}{|c|}{0} \\
\hline
\end{tabular}

L-GA: L-glutamic acid DL-PCA: DL-pyrrolidone carboxylic acid DL-PCA $\left(\mathrm{NH}_{4}\right)$ : DL-ammonium pyrolidone carboxylic acid.

4) K. V. Giri, Nature, 170, 1025 (1952)

5) M. Somogyi, J. Biol. Chem., 195, 19 (1952). 

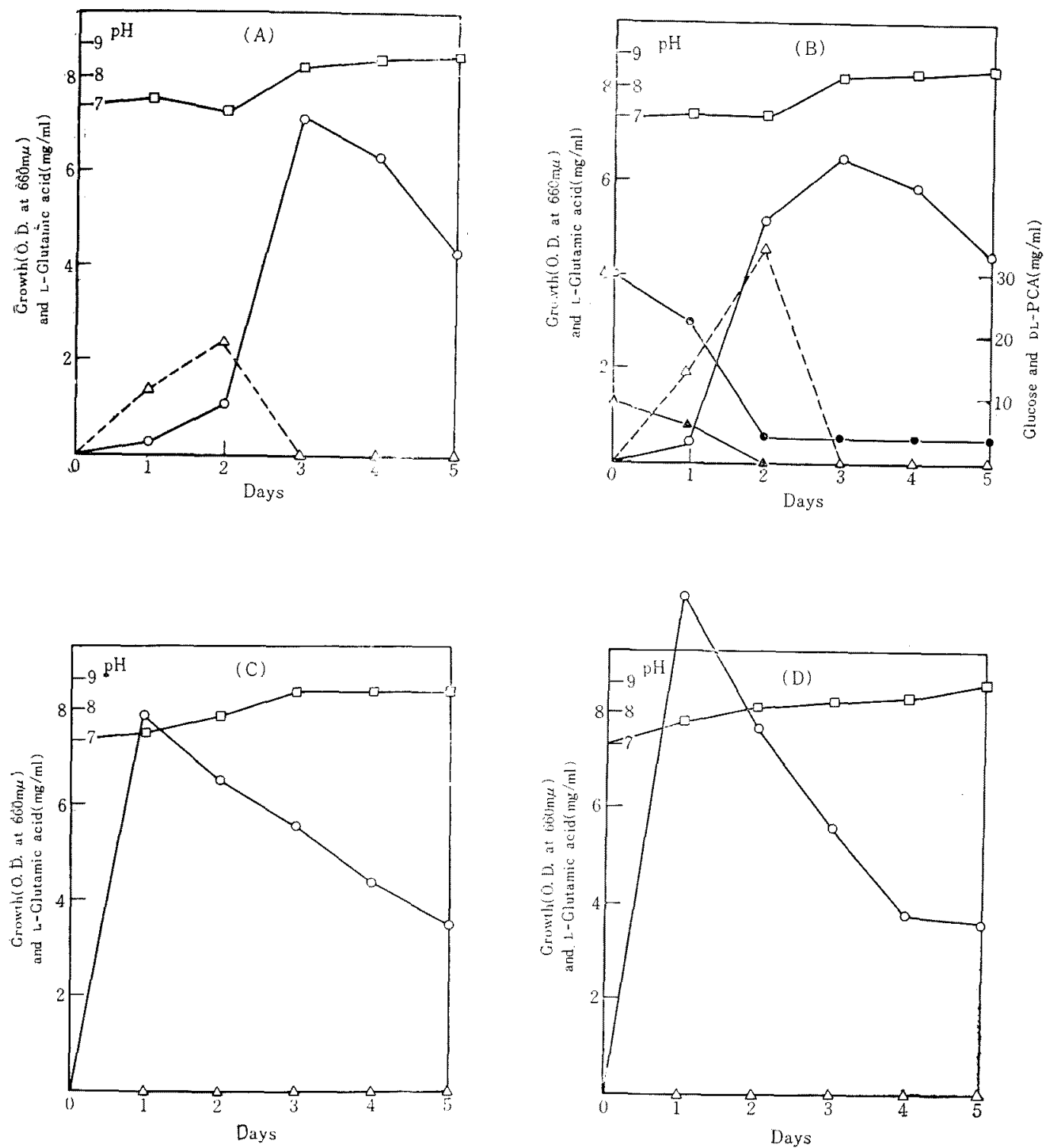

FIG. 1. Growth and L-Glutamic Acid Production in Media of 3\% Glucose-1\% Ammonium DL-Pyrrolidone Carboxylic Acid and Various Yeast Extract Concentrations.

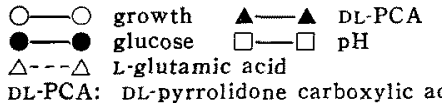
(A) $0.001 \%$ yeast extract
(B) $0.005 \%$ yeast extract
(C) $0.05 \%$ yeast extract
(D) $0.5 \%$ yeast extract

DL-PCA: DL-pyrrolidone carboxylic acid 

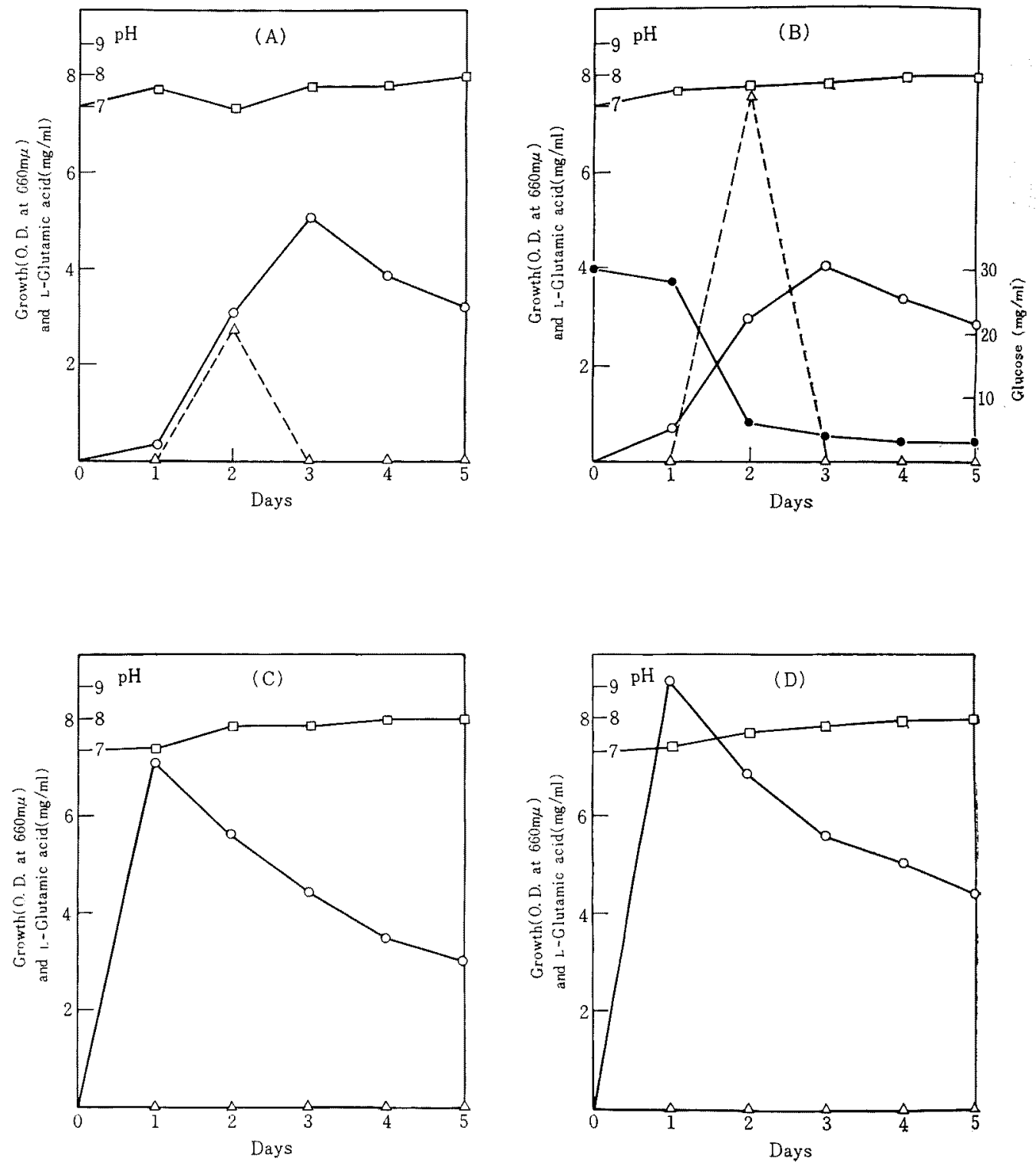

FIG. 2. Growth and L-Glutamic Acid Production in Media of 3\% Glucose-1\% Ammonium Chloride and Various Yeast Extract Concentrations.

$\begin{array}{ll}\mathrm{O}-\mathrm{O} \text { growth } & \triangle \cdots \\ \square-\triangle & \mathrm{L}-\mathrm{glutamic} \text { acid }\end{array}$ $\begin{array}{llll}\text { (A) } 0.001 \% \text { yeast extract } & \text { (B) } 0.005 \% \text { yeast extract } & \text { (C) } 0.05 \% \text { yeast extract }\end{array}$ (D) $0.5 \%$ yeast extract. 
Nomura. ${ }^{2)}$ It is further suggested from the results obtained by these tests that PCA may be utilized by the above $B$. megaterium strain as the main nitrogen source for its growth since this organism could not grow in PCA medium lacking glucose. Furthermore, ammonium salt of PGA was expected to be more favorable as the nitrogen source than free PCA, and thus, using this ammonium salt, optimal concentration of other effective nitrogen components of the medium such as yeast extracts was examined in relation to the cell growth of this strain and L-glutamic acid formation.

PCA, regardless of its form, free or ammonium salt, inhibited growth, and organic nitrogen sources, such as yeast extracts, relieved this inhibition if added in small amounts. $0.001,0.005,0.05$ and $0.5 \%$ yeast extracts, respectively, were used in the presence of $1 \%$ ammonium salt of PCA. The control contained ammonium chloride instead of ammonium salt of PCA.

Figs. 1 and 2 illustrate the results obtained. Growth was improved with increased concentrations of yeast extracts. However, production of L-glutamic acid was not observed at higher, but at lower concentrations; with $0.005 \%$ yeast extracts $4.8 \mathrm{mg} / \mathrm{ml}$ of L-glutamic acid was accumulated in 48 hours (Fig. 1).

Almost the same results as above were obtained with the control using ammonium chloride: the maximal amount of L-glutamic acid produced was also in the 48 hour culture to which $0.005 \%$ yeast extract had been added. However the yield $(7.6 \mathrm{mg} / \mathrm{ml})$ was higher than with ammonium salt of PCA. (Fig. 2). Ammonium salt of PCA is thus assumed to be less available for production of L-glutamic acid than ammonium chloride and instead prevents its production. On the other hand, the fact that yeast extracts favored cell growth but not the production of L-glutamic acid may coincide with the well-known case of glutamic acid accumulation by Brevibacterium sp. which requires biotin for its growth.
As described above, glucose was required for the growth of this $B$. megaterium strain in the PCA medium, and an optimal concentration of $3 \%$ was most favorable for both cell growth and production of L-glutamic acid.

\section{L-Glutamic Acid Production by Resting Cells}

The above results which were obtained from growing culture were further checked by using resting cells. Cells were harvested from the shaking cultures after 24 hours at $30^{\circ} \mathrm{C}$, washed twice with sterile water, and cell suspensions prepared.

The following additions to phosphate buffer solution ( $\mathrm{pH} 7.0$ ) were made: (1) $0.2 \mathrm{M}$ glucose $+0.1 \mathrm{~m}$ ammonium salt of DL-PCA, (2) $0.2 \mathrm{M}$ glucose (3) $0.2 \mathrm{M}$ DL-PCA (4) $0.2 \mathrm{~m}$ glucose + $0.1 \mathrm{M}$ ammonium chloride. Washed cell suspensions were added to each of these media so as to give a final cell concentration of ca. $10^{\circ} \mathrm{cells} / \mathrm{ml}$, then incubated at $30^{\circ} \mathrm{C}$ for $16 \sim 24$ hours in a shaking Monod-type tube. To detect the excretion of endogenous glutamic acid, cells were also added to plain phosphate buffer solution and incubated as above.

As seen from Fig. 3, about half the ammonium salt of DL-PCA was consumed after five hours incubation if in the presence of glucose, which also was exhausted during this period. The amount of L-glutamic acid produced in five hours was $1 \mathrm{mg} / \mathrm{ml}$ and reached a maximum of $1.5 \mathrm{mg} / \mathrm{ml}$ after 12 hours incubation.

In contrast, when PCA alone was added to the medium, scarcely any PCA was consumed nor any glutamic acid produced. As seen from Fig. 4, in the cases of the media lacking PCA, i.e. the media containing glucose alone or glucose together with ammonium chloride, only small amounts of glutamic acid were accumulated during 24 hours incubation and no endogenous L-glutamic acid excreted. From the results obtained with resting cells; it is presumed that the L-glutamic acid produced may be derived from both glucose and PCA, since this amino acid was accumulated only in glucose plus PGA media and accompanied 

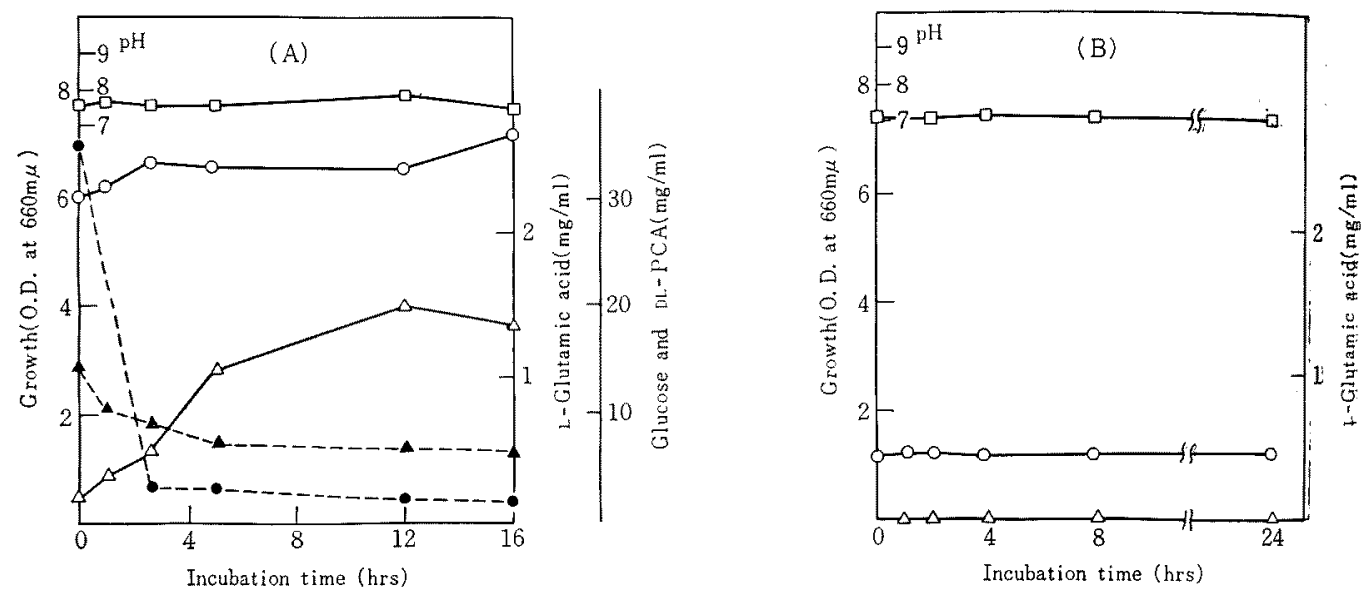

FIG. 3. L-Glutamic Acid Production by Resting Cells.

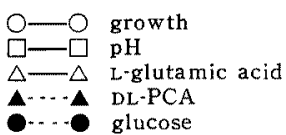

(A) substrate: $0.1 \mathrm{M} \mathrm{DL}-\mathrm{PCA}\left(\mathrm{NH}_{4}\right)+0.2 \mathrm{M}$ glucose (24 hrs culture cells)

(B) substrate: $0.1 \mathrm{M} \mathrm{DL}-\mathrm{PCA}\left(\mathrm{NH}_{4}\right)+0.2 \mathrm{M}$ glucose ( $45 \mathrm{hrs}$ culture cells)

DL-PCA $\left(\mathrm{NH}_{4}\right)$ : DL-ammonium pyrrolidone carboxylic acid

by consumption of the added PGA, but none or little in the medium of glucose alone.

A further attempt was made to study the effect of age of the seed culture on the Lglutamic acid-producing activity. For this purpose cells cultured for 45 hours were inoculated into buffer solutions containing PCA and glucose, and incubated under the same conditions as above. With these aged cells, little, if any, L-glutamic acid was accumulated, at least during 24 hours incubation. Thus, only younger cells which are exponentially proliferating are assumed to possess the capacity of L-glutamic acid formation from PCA or glucose, and this capacity is lost or greatly reduced during aging.

L-Glutamic Acid Production in Medium Containing D-Glucose-U-14C or DL-PCA-1-14 C

From the results already described, it was presumed that a part of the L-glutamic acid produced may be derived from added DL-PCA in both growing cultures and resting cells.

In growing cultures using the glucose plus PCA medium less L-glutamic acid was produced compared with the glucose plus am- monium chloride medium. With resting cells in the glucose plus PCA medium L-glutamic acid was appreciably produced only after 24 hours incubation.

A medium of the following components. was used for this purpose: $3 \%$ glucose, $0.005 \%$ yeast extracts and 1\% DL-PCA plus either $4.50 \times 10^{2}$ c.p.m./ $\mu$ mole of $\mathrm{D}$-glucose-U $-{ }^{14} \mathrm{C}$ or $1.42 \times 10^{2}$ c.p.m. $/ \mu$ mole of DL-PCA- $1{ }^{14} \mathrm{C}$. The supernatant in each case was obtained by centrifugation of the 24 hour culture and the specific radioactivity of the L-glutamic acid produced was determined. Fifty $\mathrm{ml}$ of each supernatant was concentrated in vacuo and L-glutamic acid detected by paper chromatography. After elution with distilled water the radioactivity was determined by Radiation Counter Model RSA-5 EIA (The Institute of Physical and Chemical Research).

As shown in Table II, the ratio of specific radioactivity of the added $\mathrm{D}$-glucose- $\mathrm{U}-{ }^{14} \mathrm{C}$ to the L-glutamic acid produced $(4.5 \mathrm{mg} / \mathrm{ml}$ in yield) was $4.5: 2.09$. Thus about 50 per cent radioactivity was incorporated from the $\mathrm{D}$ glucose- $\mathrm{U}-{ }^{14} \mathrm{C}$ into the L-glutamic acid pro- 

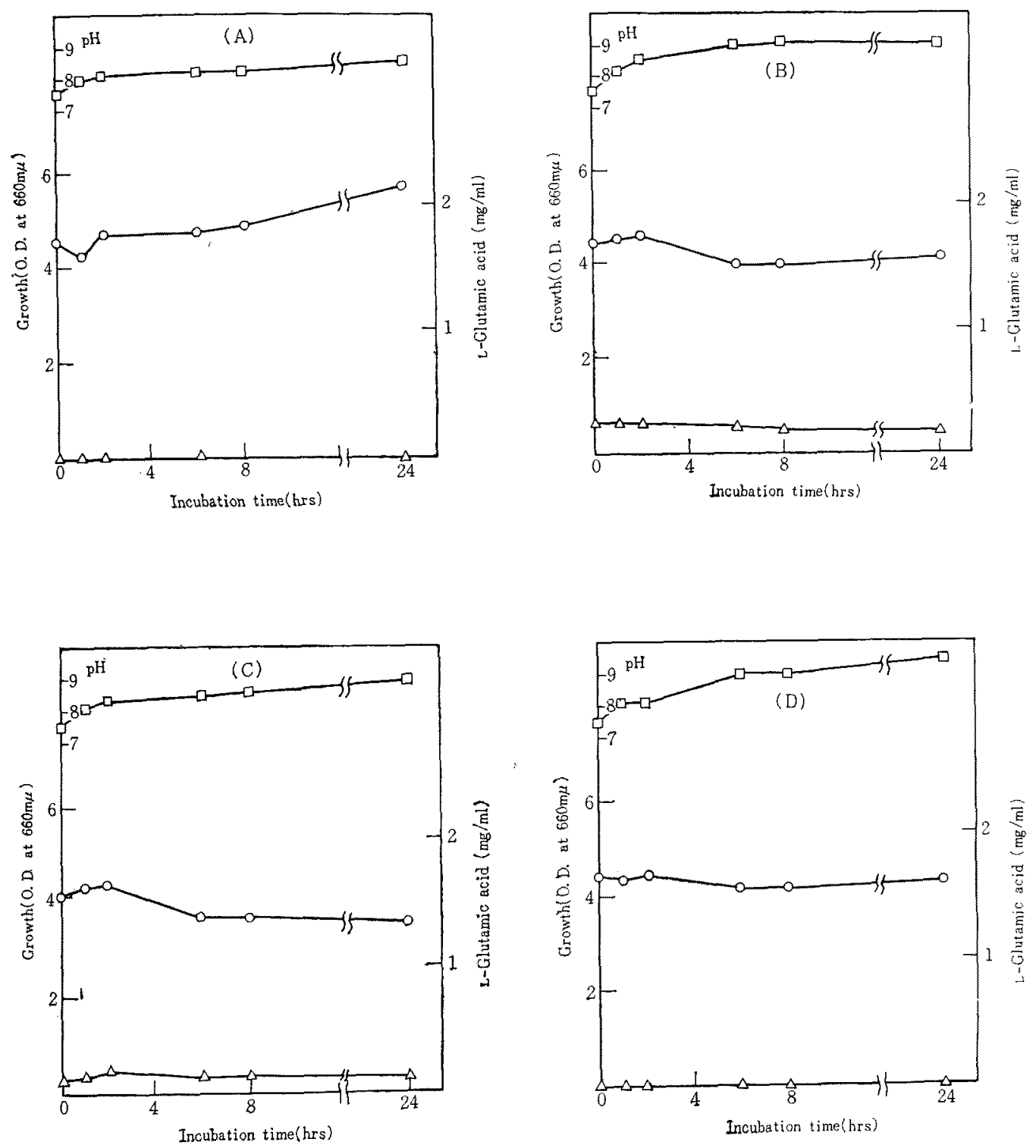

FIG. 4. L-Glutamic Acid Production by Resting Cells.

$0-\mathrm{O}$ growth

$\triangle-\triangle$ L-glutamic acid

$\square-\square \mathrm{pH}$

DL-PCA: DL-pyrrolidone carboxylic acid
(A) substrate: $0.2 \mathrm{M}$ glucose

(B) substrate: $0.2 \mathrm{M}$ DL.PCA

(C) substrate: $0.2 \mathrm{M}$ glucose, $0.1 \mathrm{M} \mathrm{NH} \mathrm{NH}_{4} \mathrm{Cl}$

(D) substrate: none. 
TABLE II. INCORPORATION OF D-GLUCOSE-U-14C OR DL-PCA-1-14C INTO L-GLUTAMIC ACID

\begin{tabular}{|c|c|c|}
\hline & $\begin{array}{c}\text { Radioactivity } \\
10^{3} \times \text { c.p.m./ml }\end{array}$ & $\begin{array}{c}\text { Specific } \\
\text { Radioactivity } \\
10^{2} \times \text { c.p.m. } / \mu \text { mole }\end{array}$ \\
\hline glucose added & 7.48 & 4.50 \\
\hline \multirow[t]{2}{*}{ glutamate formed } & 0.73 & 2.09 \\
\hline & $\begin{array}{l}\text { Radioactivity } \\
10^{6} \times \mathrm{c} . \mathrm{p} . \mathrm{m} . / \mathrm{ml} \\
\text { or } \mathrm{mg} \text { dry cell }\end{array}$ & $\begin{array}{l}\text { Specific } \\
\text { Radioactivity } \\
\text { c.p.m./ } \mu \text { mole }\end{array}$ \\
\hline PCA added & 10.99 & $1.42 \times 10^{2}$ \\
\hline glutamate formed & 0.313 & $1.25 \times 10$ \\
\hline filtrate & 0.945 & \\
\hline cells & 2.307 & \\
\hline
\end{tabular}

duced. In the case of DL-PCA- $1-{ }^{14} \mathrm{C}$ the radioactivity of the L-glutamic acid produced was considerably low and the ratio in specific radioactivity of the added $D L-P C A-1-{ }^{14} \mathrm{C}$ to the L-glutamic acid produced was $1.42 \times 10^{2}$ : $1.25 \times 10$. Thus only 10 per cent of the radioactivity of the added DL-PCA- $1-{ }^{14} \mathrm{C}$ was incorporated into the L-glutamic acid produced. However, it is noteworthy that incorporation of radioactivity from added $\mathrm{D}$-glucose- $\mathrm{U}_{-}{ }^{14} \mathrm{C}$ or DL-PCA-1 $-{ }^{14} \mathrm{C}$ into the L-glutamic acid produced occurred in each culture and, accordingly, most of the L-glutamic acid was derived from the added glucose and only a small part from the added PCA. Because of the fact that half of the added PCA was consumed by the resting cells, if in the presence of glucose, it is thought that only a small portion of the added PCA was metabolized to the glutamic acid and most of it was metabolized to some intermediates in the glutamic acid pathway. Thus, in this bacterial strain, PCA seems to undergo catalysis and cleavage of its pyrrolidone ring to form small amounts of glutamic acid or other related intermediates. The hydrolytic reaction of PCA to glutamic acid in bacterial metabolism is still unknown. Whether or not the cleavage reaction of PCA is undergone through hydrolysis, the metabolized products of PCA may be predicted to act as competing agents against the normal metabolites on the biosynthetic pathway to glutamic acid, because of the homologous nature of the cleaved products from PCA to glutamic acid or its related normal metabolites. The nature of the biosynthsis of glutamic acid can be more closely studied by using bacteria capable of assimilating PCA as the sole source of nitrogen and carbon. Further research with such bacteria is now in progress.

Acknowledgement. The authors are very much indebted to Dr. Myoda for the revision of the Englished manuscript of this report. 